\title{
Short and long term predictive value of admission wall motion score in acute myocardial infarction $A$ cross sectional echocardiographic study of 345 patients
}

\author{
GERARD KAN,^ CEES A VISSER, JACQUES J KOOLEN, AREND J DUNNING
}

From the Department of Cardiology, Academisch Medisch Centrum, University of Amsterdam; and the Interuniversity Cardiology Institute, Utrecht, The Netherlands

SUMMARY A score of left ventricular segmental wall motion was used as a convenient rapid way to assess overall left ventricular function in acute myocardial infarction. Its success in risk stratification at admission was assessed by a blind review of cross sectional echocardiographic tape recordings from multiple acoustic windows. Sixty nine $(20 \%)$ of the 345 patients died during hospital stay or within a one year follow up. The mean (SD) wall motion score in those who died was significantly higher than in those who survived $(16.2(5.9)$ vs $5.7(3.9))$. There were no differences between the group that died in hospital within three months of discharge and the group that died between three months and one year after discharge. Among the 31 patients who died in hospital, however, wall motion score was highest in 15 patients dying of cardiogenic shock $(19 \cdot 2(4 \cdot 2))$. In 16 patients with lethal ruptures it was $13.5(6 \cdot 1)$. The nine patients with free wall ruptures had higher wall motion scores than those with ventricular septal rupture or papillary muscle rupture (15.7 (6.9) vs $8.5(5.3))$. Eight (3.3\%) of 245 patients with a score < 10 died, compared with $61(61 \%)$ of 100 scoring $\geqslant 10$. The sensitivity of a score of $\geqslant 10$ in predicting death within one year was $88 \%$, the specificity was $86 \%$, the positive predictive value was $61 \%$, and the negative predictive value was $97 \%$.

Cross sectional echocardiography is capable of detecting ${ }^{12}$ and quantifying ${ }^{3-6}$ acute myocardial infarction. It can be performed at the bedside with considerable success and at low cost and it provides a rapid impression of global left ventricular function. There have been studies in which left ventricular function was assessed by a segment score ${ }^{7-9}$ or by calculation of ejection fraction, ${ }^{910}$ and in which the results obtained were correlated with signs of pump failure and mortality. Calculation of ejection fraction has the attraction of being quantitative but it requires time and equipment and in most cases

Requests for reprints to Dr Gerard Kan, Department of Cardiology, Elisabeth Gasthuis, Boerhaavelaan 22, 2035 RC Haarlem, The Netherlands.

*Present address: Elisabeth Gasthuis, Boerhaavelaan 22, Haarlem, The Netherlands.

Accepted for publication 25 March 1986 cannot be done at the bedside. A segment score requires no computer facilities and may be done at the bedside. It gives semiquantitative and reproducible $^{56}$ results that correlate well with infarct size as determined by pathology, ${ }^{3}$ scintigraphy, ${ }^{4}$ or peak concentrations of creatine kinase MB. ${ }^{5} 6$

Because infarct size is an important prognostic indicator we undertook the present investigation to assess the prognostic value of infarct size assessed shortly after admission by a cross sectional echocardiographic wall motion score in a large representative group of patients with acute myocardial infarction. The primary end point was death during hospital stay and throughout a one year follow up.

\section{Patients and methods}

PATIENTS

From June 1981 to June 1983, 1365 patients were 
admitted to the coronary care unit of the academic hospital of the University of Amsterdam. Of these, 517 had acute myocardial infarction as defined below. All patients with infarction qualified for inclusion in the study; we studied 370 who had cross sectional echocardiography within 12 hours of admission. No specific age limits were set nor was a previous infarct a reason for exclusion. In 345 images of sufficient quality for complete segmental analysis were obtained (success rate $93 \%$ ). The study was prospective.

\section{CROSS SECTIONAL ECHOCARDIOGRAPHY}

A Smith-Kline EkoSector 10A was used during the first half of the study period and an ATL Mark 300 during the second half. Both are mechanical sector scanners with pulse frequencies of 2.25 and 3.0 $\mathrm{MHz}$ respectively. We used a standard approach in which multiple acoustic windows and both short and long axis cross sectional views were obtained with the patient in the left lateral decubitus position.

For purposes of analysis we used three apical long axis views (fig), recorded at mutual angles of $60^{\circ}$ with the aid of a calibrated fluid filled ring containing an air bubble that was fixed around the body of the transducer. ${ }^{11}$ These three views were the apical long axis or three chamber view, the four chamber view, and the two chamber view. In each of these views the left ventricular contour was divided into five segments. The apical area was regarded as one segment common to all three views, so that a total of 13 segments was obtained. Where one or more segments could not be visualised from the apex we used parasternal long and short axis views (or in some cases subcostal views). Each segment was assigned a numerical value according to the degree of systolic wall motion abnormality that it showed: 0 for normokinesis, +1 for hypokinesis, +2 for akinesis, and +3 for dyskinesis. Hyperkinesis (defined as exaggerated wall motion and myocardial thickening ${ }^{8}$ ) was graded -1 . Left ventricular aneurysm (defined as a bulge in the left ventricular contour that persisted in both diastole and systole and showed akinesis or dyskinesis) was graded +4 .

\section{DIAGNOSTIC CRITERIA}

The diagnosis of acute myocardial infarction was based on a typical history with evolving electrocardiographic changes or a diagnostic rise and fall in the activities of cardiac isoenzyme (MB) of creatine kinase or both. A value of more than twice the upper limit of normal (4 U/1) was considered to be abnormal. Infarct size was estimated from the peak value of creatine kinase, which for this purpose was sampled every four hours until a peak and a fall were seen.

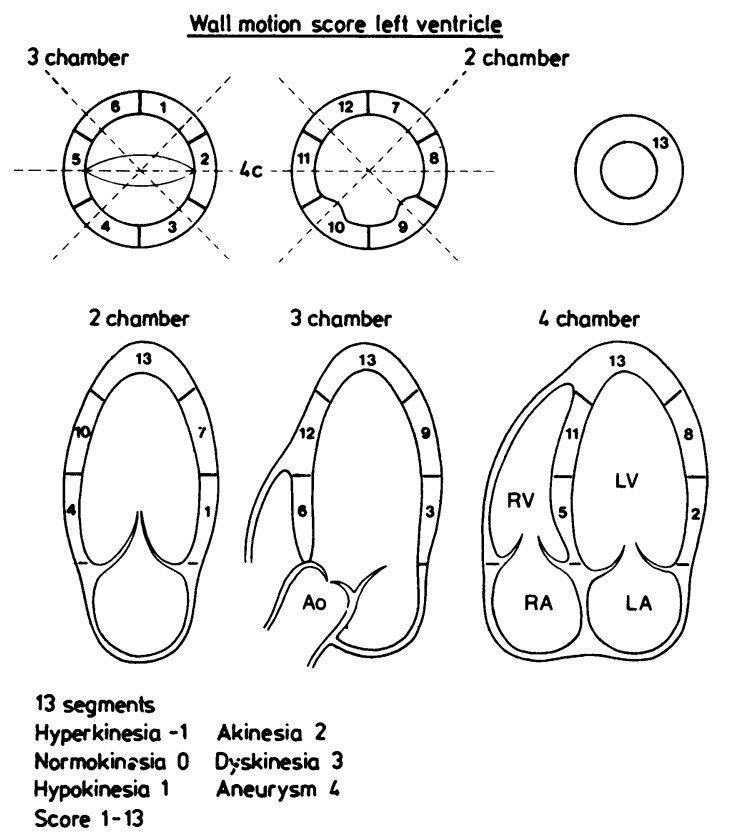

Figure Diagram of the three apical long axis views (lower panel) used for calculation of the left ventricular wall motion score. In each of the three views the left ventricular myocardium was divided into five segments; the apex was considered to be common to all three apical views. If the apical views were not adequate for analysis, the same segments could be evaluated from short axis cross sections (upper panel). The three chamber view was a long axis view or right anterior oblique equivalent. Ao, aorta; $L A$, left atrium; $L V$, left ventricle; $R A$, right atrium; $R V$, right ventricle.

Infarct localisation was determined electrocardiographically by the criteria of the New York Heart Association. ${ }^{12}$ All septal, anterior, and lateral infarcts were grouped as anterior, and all inferior and posterior infarcts as posterior. Patients with pre-existing electrocardiographic abnormalities (such as pacemaker rhythm, left bundle branch block, or Wolff-Parkinson-White syndrome) were designated as non-localisable infarcts.

\section{FOLLOW UP AND STATISTICAL ANALYSIS}

Follow up data such as time and mode of death were obtained in all cases from the patients' cardiologist either by inspection of records or by telephone (if the patient was seen in another hospital for follow up). If the patient was not under the care of a cardiologist his family physician was contacted. Vital status was known for each patient at one year.

For between group comparisons Student's $t$ test and $\chi^{2}$ analysis were used where appropriate. Mor- 
tality results were analysed separately for the inhospital period and for one year after hospital discharge. The year after discharge was subdivided into periods from discharge to three months and from three months to one year because most of the deaths in the first year occur during the early months after infarction. ${ }^{13}$

\section{Results}

STUDY GROUP AND MORTALITY

We studied 345 patients ( 265 men and 80 women, mean (1 SD) age 62 (12) years, range 32-86 years)). Of these, $69(20 \%)$ patients died during the one year follow up period (31 died in hospital, 16 died within 3 months of discharge, and 22 between three months to 1 year of discharge). Of the 31 patients dying in hospital, 15 died of cardiogenic shock and 16 of cardiac rupture (free wall rupture in nine, ventricular septal rupture in five, and papillary muscle rupture in two). Free wall rupture was diagnosed by postmortem examination in six patients and by the typical clinical picture of sudden electromechanical dissociation in the remaining three. Ventricular septal rupture or papillary muscle rupture was recognised by the development of sudden haemodynamic deterioration in conjunction with the appearance of a new murmur and was confirmed by cardiac catheterisation in all patients. During the two year period of the study, another six patients were successfully operated upon for papillary muscle rupture (one patient) or ventricular septal rupture (five patients). The mortality rate for all patients with ventricular septal rupture or papillary muscle rupture was $54 \%(7 / 13)$.

Sixteen patients died within three months of discharge from hospital. In four the mode of death was fatal reinfarction, four patients died suddenly, one died from late ventricular arrhythmias, two from pump failure (postoperative in one), and one had a fatal cerebrovascular accident. In four the cause of death was not certain, but seems most likely to have been sudden because it occurred outside hospital. Necropsies were not performed in these cases, however, so we do not know whether these deaths were caused by late arrhythmias without reinfarction or by lethal reinfarctions with primary ventricular fibrillation or pump failure.

Of the 22 patients dying three months to one year after discharge, seven sustained lethal reinfarctions, two died suddenly, one died from ventricular arrhythmias, and four from pump failure (postoperative in two); in eight the mode of death was unknown, again these were most likely to be sudden deaths.

Table 1 gives the mean ages, infarct site, and infarct size (peak creatine kinase MB) for survivors and non-survivors. Patients who died were older than surviving patients $(65$ (10) vs $60(12)$ years, $p<$ 0.001 ), had higher peak creatine kinase MB values (197 (105) vs 117 (76), $\mathrm{p}<0.01$ ), and more anterior infarcts $\left(72 \%\right.$ versus $47 \% ; p<0.005 ; \chi^{2} 16.7 ; 2$ degrees of freedom).

\section{WALL MOTION SCORE AND MORTALITY}

Table 2 shows the results of wall motion score in survivors and non-survivors. Non-survivors had a much higher wall motion score than survivors $(16 \cdot 2$ (5.9) vs 5.7 (3.9); $p<0.001)$. Among those who died there were no group differences in wall motion score between the in-hospital deaths, those dying within three months, and those who died between three months and one year. Table 3, however, shows that among the 31 patients dying in hospital the highest wall motion scores were seen in those dying of primary cardiogenic shock (19.2 (4.2)). Their wall motion score was significantly higher $(p<0.05)$ than that of the patients dying of ruptures $(13.5$ $(6 \cdot 1)$.

Within the subgroup of patients with ruptures those with free wall ruptures had higher wall motion scores than those with papillary muscle rupture and ventricular septal rupture $(15 \cdot 7(6.9)$ vs $8.5(5.3)$, $\mathrm{p}<0.05)$.

Table 1 Mortality in relation to infarct site and size

\begin{tabular}{|c|c|c|c|c|c|c|c|c|c|c|c|}
\hline & \multirow[b]{2}{*}{ No } & \multirow[b]{2}{*}{ Age (yr) } & \multicolumn{8}{|c|}{ Infarct site } & \multirow[b]{2}{*}{$\begin{array}{l}\text { Peak } C K-M B \\
(U / l)\end{array}$} \\
\hline & & & $\begin{array}{l}A \\
\text { No }\end{array}$ & $\%$ & $\begin{array}{l}P \\
\text { No }\end{array}$ & $\%$ & $\begin{array}{l}A+ \\
\text { No }\end{array}$ & $\begin{array}{l}P \\
\%\end{array}$ & $\begin{array}{l}n l \\
\text { No }\end{array}$ & $\%$ & \\
\hline \multirow{3}{*}{$\begin{array}{l}\text { Survivors } \\
\text { Non-survivors } \\
\text { In-hospital deaths } \\
\text { Died } \leqslant 3 \text { months from } \\
\text { discharge } \\
\text { Died between three months } \\
\text { and one year }\end{array}$} & $\begin{array}{r}276 \\
69 \\
31\end{array}$ & $\begin{array}{l}60(12)^{\star} \\
65(10)^{\star} \\
66(11)\end{array}$ & $\begin{array}{r}130 \\
50 \\
22\end{array}$ & $\begin{array}{l}47 \star \star \\
72^{\star \star} \\
71\end{array}$ & $\begin{array}{r}102 \\
9 \\
5\end{array}$ & $\begin{array}{l}40^{\star \star} \\
13^{\star \star} \\
16\end{array}$ & $\begin{array}{r}23 \\
6 \\
4\end{array}$ & $\begin{array}{l}8 \\
9 \\
13\end{array}$ & $\begin{array}{r}21 \\
4 \\
0\end{array}$ & $\begin{array}{l}8 \\
6\end{array}$ & $\begin{array}{l}117(76)^{\star} \\
197(108)^{\star} \\
185(101)\end{array}$ \\
\hline & 16 & $65(12)$ & 12 & 75 & 1 & 6 & 1 & 6 & 2 & 12 & $235(119)$ \\
\hline & 22 & $65(10)$ & 16 & 73 & 3 & 14 & 1 & 4 & 2 & 9 & $196(105)$ \\
\hline
\end{tabular}

$\mathrm{A}$ anterior; $\mathrm{P}$, posterior; $\mathrm{A}+\mathrm{P}$, anterior + posterior; $\mathrm{nl}$, non-localisable; $\mathrm{CK}-\mathrm{MB}$, creatine kinase $\mathrm{MB}$ isoenzyme, ${ }^{\star} \mathrm{p}<0.001$; $\star_{\star \star k} p<0.005\left(\chi^{2}=16 \cdot 7 ; 2\right.$ degrees of freedom): comparison between survivors and non-survivors. 
Table 2 Mortality in relation to wall motion score

\begin{tabular}{|c|c|c|c|}
\hline & \multirow[b]{2}{*}{ No } & \multicolumn{2}{|c|}{ Wall motion score } \\
\hline & & Mean $(S D)$ & Range \\
\hline \multirow{5}{*}{$\begin{array}{l}\text { Survivors } \\
\text { Non-survivors } \\
\text { In-hospital deaths } \\
\text { Died } \leqslant 3 \text { months from } \\
\text { discharge } \\
\text { Died between } 3 \text { months } \\
\text { and } 1 \text { year }\end{array}$} & 276 & $5.7(3.9)^{\star}$ & -3 to +21 \\
\hline & 69 & $16 \cdot 2(5 \cdot 9)^{\star}$ & -2 to +26 \\
\hline & 31 & $16 \cdot 2(6 \cdot 0)$ & -2 to +26 \\
\hline & 16 & $16.4(5.4)$ & +2 to +26 \\
\hline & 22 & $16 \cdot 4(4 \cdot 0)$ & +4 to +24 \\
\hline
\end{tabular}

${ }^{\star} \mathrm{p}<0.001$ for this comparison.

Table 3 Wall motion score in patients dying in hospital, in relation to cause of death

\begin{tabular}{lrlr}
\hline & & \multicolumn{2}{l}{ Wall motion score } \\
\cline { 3 - 3 } Cause & No & Mean (1 SD) & Range \\
\hline CS & 15 & $19 \cdot 2(4 \cdot 2)$ & +12 to +26 \\
All ruptures & 16 & $13 \cdot 5(6 \cdot 1)$ & -2 to +24 \\
FWR & 9 & $15 \cdot 7(6 \cdot 9)$ & +1 to +24 \\
PMR or VSR & 7 & $8 \cdot 5(5 \cdot 3)$ & -2 to +15 \\
\hline
\end{tabular}

CS, cardiogenic shock; FWR, free wall rupture; PMR, papillary muscle rupture; VSR, ventricular septal rupture.

$\mathrm{CS}$ vs all ruptures, $\mathrm{p}<0.05 ;$ FWR $v S$ PMR or VSR, $\mathrm{p}<0.05$

Table 4 shows deaths in patients with high $(\geqslant 10)$ or low $(<10)$ wall motion scores. This cut off value of 10 was chosen empirically to give the sharpest separation with the best sensitivity and specificity trade-off. Of the 69 deaths, 61 occurred in the group with high wall motion scores and eight in the group with low wall motion scores (mortality rates were $61 \%$ and $3.3 \%$ respectively). Table 5 shows the sensitivity and specificity of a high $(\geqslant 10)$ wall motion score for recognition of patients dying within the

Table 4 Hospital mortality and late mortality in patients with wall motion score (WMS) $<10$ versus $\geqslant 10$

\begin{tabular}{|c|c|c|c|c|c|c|}
\hline \multirow[b]{2}{*}{$W M S$} & \multirow[b]{2}{*}{ No } & \multirow[b]{2}{*}{ In hospital } & \multirow[b]{2}{*}{$\leqslant 3$ months } & \multirow{2}{*}{$\begin{array}{l}3 \text { months- } \\
1 \text { year }\end{array}$} & \multicolumn{2}{|c|}{ Total } \\
\hline & & & & & No & $\%$ \\
\hline $\begin{array}{l}<10 \\
\geqslant 10\end{array}$ & $\begin{array}{l}245 \\
100\end{array}$ & $\begin{array}{r}4 \\
27\end{array}$ & $\begin{array}{r}3 \\
13\end{array}$ & $\begin{array}{r}1 \\
21\end{array}$ & $\begin{array}{r}8 \\
61\end{array}$ & $\begin{array}{l}3 \cdot 3 \\
61\end{array}$ \\
\hline
\end{tabular}

WMS $<10$ vs WMS $\geqslant 10, \mathrm{p}<0.001$.

Table 5 Sensitivity and specificity of a wall motion score $(W M S) \geqslant 10$ in prediction of all mortality

\begin{tabular}{llll}
\hline WMS & Deaths & Survivors & Total \\
\hline$\geqslant 10$ & 61 & 39 & 100 \\
$<10$ & 8 & 237 & 245 \\
& 69 & 276 & 345
\end{tabular}

Sensitivity $61 / 69,88 \%$; positive predictive value $61 / 100,61 \%$; specificity $237 / 276,86 \%$; negative predictive value: $237 / 245,97 \%$; total predictive accuracy: $298 / 345,86 \%$. one year study period. Sensitivity is $88 \%$ and specificity $86 \%$. The predictive value of a positive test (high score) for death is $61 \%$ and that of a negative test (low score) for survival is $97 \%$.

\section{Discussion}

\section{PREVIOUS CROSS SECTIONAL \\ ECHOCARDIOGRAPHIC STUDIES IN ACUTE \\ INFARCTION}

Heger et al were among the first to report on the detection and localisation of acute myocardial infarction by cross sectional echocardiography. ${ }^{1}$ They found good agreement between the site of infarction determined by echocardiography and that determined by electrocardiography. Horowitz et al showed that cross sectional echocardiography can diagnose infarction before the results of other tests are known. ${ }^{2}$

Quantification of the amount of left ventricular myocardium affected by the infarct is another important issue. There is little information on the correlation between echocardiographic infarct size and infarct size at necropsy. ${ }^{3}$ Echocardiography overestimated the infarct size at necropsy but in general the correlation was good and other studies have shown equally good correlations between infarct sizes assessed by echocardiography and scintigraphy (both thallium-201 and technetium-99m pyrophosphate $)^{4}$ and those assessed by echocardiography and peak creatine kinase. ${ }^{56}$

The ejection fraction is a convenient way of expressing global left ventricular function, and the ejection fraction measured by radionuclide angiography has been shown to be useful for recognition of high risk subgroups. ${ }^{1415}$ Notably, an ejection fraction of $<30 \%{ }^{14}$ or $<35 \%{ }^{15}$ has been shown to carry with it the risk of pump failure and death. Our group also found that the extent of left ventricular dysfunction-expressed again as an ejection fraction - can be assessed shortly after admission by cross sectional echocardiography, and this method had a comparable predictive value. ${ }^{10}$

The exhaustive study by Van Reet $e t$ al found that cross sectional echocardiography and radionuclide angiography were of equal value in this respect. ${ }^{9}$ Measurement of ejection fraction from cross sectional echocardiograms, however, is time consuming and requires computer facilities. Moreover, in some cases the need to use still frames from tape recordings results in suboptimal endocardial definition which makes volume calculations impossible. In contrast a segmental wall motion score provides a good impression of overall ventricular function without the necessity to make any geometric assumptions. It requires little time (because record- 
ings can be reviewed at normal speed) and has a higher success rate than would be obtained if an ejection fraction were to be calculated. In the present study success rate was $93 \%$ compared with the $80 \%$ rate in our ejection fraction study. ${ }^{10}$

Because we had already found that the area of asynergy changes little in the days after the acute infarct $^{5}$ we analysed the tape recordings of all patients in whom echocardiography had been performed within the early hours of admission. Others have reported that echocardiographic data obtained in the earliest stages of infarction have important prognostic implications. ${ }^{81016}$ Some of these studies, the largest being that of Van Reet $e t$ al, focused on in-hospital death. ${ }^{9}$ They and Nishimura et al used a wall motion score obtained before discharge to predict mortality after discharge for up to one year. ${ }^{17}$ In contrast our study was based on a single wall motion score obtained shortly after admission and we considered total mortality-that is in hospital and for up to one year after discharge.

\section{PRESENT FINDINGS}

We found that total mortality in the first year after infarction was much higher in patients with a high wall motion score than that in patients with a low wall motion score (a cut off value of $<10$ or $\geqslant 10$ gave the best results in terms of separation of the two groups). This difference in mortality rates was seen both during the in-hospital phase and after discharge. Thus patients may be identified as being at high risk of death (with a sensitivity of $88 \%$, a specificity of $86 \%$, and a total predictive accuracy of $86 \%$ ) but one cannot predict whether death will occur in or out of hospital. The distribution of postdischarge mortality into an early period (up to three months) and a later one (three months to one year) showed the typical pattern, with about half of these deaths occurring during the first three months. ${ }^{17}$ Mean wall motion score in these subgroups was essentially the same. Patients dying in hospital from primary pump failure (that is cardiogenic shock) had higher wall motion score than those dying of ruptures, especially ventricular septal or papillary muscle rupture. Patients with ruptures often have histologically small infarcts. ${ }^{18}$ Patients with free wall rupture had infarcts that were intermediate in extent between septal or papillary muscle ruptures and pump failure deaths.

\section{LIMITATIONS OF THE PRESENT STUDY}

Our method is a semiquantitative one; quantitative analysis systems are available. Loh et al showed that a wall motion score very similar to the one used here was better than quantitative segmental analysis in the recognition of patients with acute non- transmural myocardial infarction. ${ }^{19}$ They also showed excellent interobserver agreement (there was a difference of only two points in two out of 300 segments). In the present study we did not do a formal analysis of interobserver variability because our laboratory in the recent past has demonstrated a consistent interobserver agreement in the assessment of wall motion in coronary artery disease. ${ }^{561020}$ An additional argument in favour of the semiquantitative approach is its higher success rate. Since most echocardiograms were obtained immediately after admission and before any interventions we did not take into account the possible confounding effects of medication. In our experience and that of others the extent of wall motion abnormalities shows little or no change over the first day (up to 10 days). ${ }^{59}$ More recently, Wilkins et al using quantitative analysis also found no significant change up to 12 weeks. ${ }^{20}$

The sensitivity, specificity, and predictive value of any test depends on the mortality rate. For the reasons discussed above we think that our study population is typical of an infarct population admitted to a modern coronary care unit, and the mortality figures (31 or $9 \%$ in hospital and 38 or $11 \%$ after discharge) seem to confirm this.

In conclusion we have rapidly and non-invasively determined the extent of the acute insult shortly after admission in a large group of patients with acute myocardial infarction. There was a fairly sharp distinction between patients with a low and high likelihood of death in the year after the infarct. This provides us with a convenient method of risk stratification at the bedside, which may be of help in patient management.

We thank Harry de Koning and Marga van CorlerWiltenburg for technical assistance.

\section{References}

1 Heger JJ, Weyman AE, Wann LS, Dillon JC, Feigenbaum $\mathrm{H}$. Cross-sectional echocardiography in acute myocardial infarction: detection and localization of regional left ventricular asynergy. Circulation 1979;60:581-8.

2 Horowitz RS, Morgenroth J, Parotto C, Chen CC, Soffer J, Pauletto FJ. Immediate diagnosis of acute myocardial infarction by two-dimensional echocardiography. Circulation 1982;65:323-9.

3 Weiss JL, Bulkley BH, Hutchins GM, Mason SJ. Two-dimensional echocardiographic recognition of myocardial injury in man: comparison with postmortem studies. Circulation 1981;62:401-8.

4 Nixon JV, Narahara KA, Smitherman TC. Estimation of myocardial involvement in patients with acute myocardial infarction by two-dimensional echocardiography. Circulation 1980;62:1248-55.

5 Visser CA, Lie KI, Kan G, Meltzer R, Durrer D. 
Detection and quantification of acute, isolated myocardial infarction by two-dimensional echocardiography. Am f Cardiol 1981;57:1020-5.

6 Visser CA, Kan G, Lie KI, Becker AE, Durrer D. Apex two dimensional echocardiography. Alternative approach to quantification of acute myocardial infarction. Br Heart $\mathcal{F}$ 1982;47:461-7.

7 Heger JJ, Weyman AE, Wann LS, Rogers EW, Dillon JC, Feigenbaum H. Cross-sectional echocardiographic analysis of the extent of left ventricular asynergy in acute myocardial infarction. Circulation 1980;61:1113-8.

8 Gibson RS, Bishop HL, Stamm RB, Crampton RS, Beller GA, Martin RP. Value of early twodimensional echocardiography in patients with acute myocardial infarction. Am $\mathcal{F}$ Cardiol 1982;49:1110-9.

9 Van Reet RE, Quinones MA, Poliner LR, et al. Comparison of two-dimensional ventriculography in the evaluation of global and regional left ventricular function in acute myocardial infarction. $\mathcal{F} \mathrm{Am}$ Coll Cardiol 1984;3:243-52.

10 Kan G, Visser CA, Lie KI, Durrer D. Early twodimensional echocardiographic measurement of left ventricular ejection fraction in acute myocardial infarction. Eur Heart $\mathcal{f}$ 1984;5:210-7.

11 Visser CA, Kan G, Dunning AJ. A simple device to obtain reproducible echocardiographic apical crosssections. Am $\mathcal{F}$ Cardiol 1985;56:206-7.

12 Criteria Committee of the New York Heart Association. Nomenclature and criteria for diagnosis of diseases of the heart. 7th ed. Boston: Little Brown, 1973:98-123.

13 Epstein SE, Palmeri ST, Patterson RE. Evaluation of patients after acute myocardial infarction. Indications for cardiac catheterization and surgical intervention. $N$ Engl f Med 1982;307:1487-92.

14 Shah PK, Pichler M, Berman DS, Singh BN, Swan HJC. Left ventricular ejection fraction determined by radionuclide ventriculography in early stages of first transmural myocardial infarction. Relation to short-term prognosis. Am $\mathcal{F}$ Cardiol 1980;45:542-6.

15 Sandford CF, Corbett J, Nicod P, et al. Value of radionuclide ventriculography in the immediate characterization of patients with acute myocardial infarction. Am f Cardiol 1982;49:637-43.

16 Horowitz RS, Morganroth J. Immediate detection of early high-risk patients with acute myocardial infarction using two-dimensional echocardiographic evaluation of left ventricular regional wall motion abnormalities. Am Heart f 1982;103:814-22.

17 Nishimura RA, Reeder GS, Miller FA Jr, et al. Prognostic value of predischarge 2-dimensional echocardiogram after acute myocardial infarction. $A m \mathcal{F}$ Cardiol 1984;53:429-32.

18 Wei JY, Hutchins GM, Bulkley BH. Papillary muscle rupture in fatal acute myocardial infarction. A potentially treatable form of cardiogenic shock. Ann Intern Med 1979;90:149-53.

19 Loh IK, Charuzi Y, Beeder C, Marshall LA, Ginsbury JH. Early diagnosis of nontransmural infarction by two-dimensional echocardiography. Am Heart $\mathcal{F}$ 1982;104:963-8.

20 Wilkins GT, Guyer DE, Weise UB, Weyman AE. Cross-sectional echocardiographically derived endocardial surface maps in acute myocardial infarction [Abstract]. Circulation 1985;72 (suppl III):III 428. 